\title{
Isolation and Identification of Microbes that Tolerate Heavy Metals ${ }^{\dagger}$
}

\author{
Yasmin Sameera S. ${ }^{1, *}$ \\ 1 Department of Microbiology, Kamaraj College, Thoothukudi-628002, Tamil Nadu \\ * Correspondence: yaasminsameera@gmail.com; \\ $\dagger$ Presented at International e-Conference on Bioengineering for Health and Environment (ICBHE 2020)
}

Received: 5.07.2020; Revised: 10.07.2020; Accepted: 12.07.2020; Published: 15.07.2020

\begin{abstract}
The greatest pollution earth is facing today is heavy metal pollution. So, there is a necessity to find a remedy to clear up this problem. A study was undergone by isolating the bacteria and fungi from the contaminated soil samples by determining its characteristics to resist heavy metals. Several methods have been determined to control the occurrence of the substances in the environment. Studies have shown that the isolated microbes have shown minimal inhibitory concentration. This can be used as a bioremediation method to drive away from heavy metal pollution as much as possible.
\end{abstract}

Keywords: Heavy metal pollution; Bioremediation; Microbes; Minimal Inhibitory Concentration.

(C) 2020 by the authors. This article is an open-access article distributed under the terms and conditions of the Creative Commons Attribution (CC BY) license (https://creativecommons.org/licenses/by/4.0/).

\section{Funding}

This research received no external funding.

\section{Acknowledgments}

This research has no acknowledgment.

\section{Conflicts of Interest}

The authors declare no conflict of interest. 